MOTA, W.F.; FINGER, F.L.; SILVA, D.J.H.; CORRÊA, P.C.; FIRME, L.P.; NEVES, L.L.M. Caracterização físico-química de frutos de quatro cultivares de quiabo. Horticultura Brasileira, Brasília, v.23, n.3, p.722-725, jul-set 2005.

\title{
Caracterização físico-química de frutos de quatro cultivares de quiabo
}

\author{
Wagner F. da Mota ${ }^{1}$; Fernando Luiz Finger²; Derly José H. da Silva²; Paulo César Corrêa ${ }^{3}$; Lúcia P. \\ Firme $^{2}$; Ludmila L. de M. Neves ${ }^{4}$ \\ ${ }^{1 /}$ UNIMONTES, Depto. Ciências Agrárias, 39440-000 Janaúba-MG; ${ }^{2 / U F V, ~ D e p t o . ~ F i t o t e c n i a, ~ 36571-000 ~ V i c ̧ o s a-M G ; ~}{ }^{3 / U F V, ~ D e p t o . ~}$ \\ Eng. Agrícola, 36571-000 Viçosa-MG; ${ }^{4}$ UFV, Depto. Biologia Vegetal, 36.571-000 Viçosa-MG; E-mail: wagner.mota@ unimontes.br
}

\section{RESUMO}

Efetuou-se a caracterização físico-química dos frutos de quatro cultivares de quiabo neste estudo. O delineamento utilizado foi de blocos casualizados, sendo os tratamentos constituídos pelas cultivares Amarelinho, Red Velvet, Star of David e Mammoth Spinless, com cinco repetições. Na maturidade comercial os frutos da cultivar Star of David tiveram maior diâmetro, peso fresco total e teor de matéria seca, menor comprimento, teor de umidade e de vitamina $\mathrm{C}$ comparado com as demais cultivares. A cultivar Red Velvet teve o menor diâmetro, peso fresco, teor de matéria seca, açúcares redutores e teores de clorofilas a, b e total, e maior teor de umidade e vitamina C. Frutos da cultivar Mammoth Spinless apresentaram os maiores teores de clorofilas a, b e total. A cultivar Amarelinho teve maior comprimento e menores teores de clorofila, a, b e total. As cultivares Amarelinho e Mammoth Spinless apresentaram maiores teores de açúcares redutores.

Palavras-chave: Abelmoschus esculentus, carboidratos, vitamina C.

\begin{abstract}
Physical and chemical characteristics from fruits of four okra cultivars

In an experiment some physical and chemical characteristics of four okra cultivars were evaluated. The experimental design was of randomized blocks, where the treatments were the cultivars Amarelinho, Red Velvet, Star of David and Mammoth Spinless with five replications. At commercial maturity fruits of the cultivar Star of David presented the largest diameter, total fresh matter, content of dry matter, smallest length, content of water and vitamin $\mathrm{C}$ in comparison to the other cultivars. The cultivar Red Velvet presented the smallest diameter, total fresh matter, content of dry matter, reducing sugars and content of chlorophyll a, b and total, but the largest content of water and vitamin C. The cultivar Amarelinho produced the longest fruits and the smallest content of chlorophyll a, b and total. The cultivars Amarelinho and Mammoth Spinless showed higher contents of total reducing sugars.
\end{abstract}

Keywords: Abelmoschus esculentus, carboidrates, Vitamin C.

(Recebido para publicação em 12 de abril de 2004 e aceito em 18 de abril de 2005)

$\mathrm{O}$ quiabo encontra no Brasil condições excelentes para o seu cultivo, principalmente no que diz respeito ao clima, sendo popularmente cultivado nas regiões Nordeste e Sudeste. A planta apresenta algumas características desejáveis como ciclo rápido, custo de produção economicamente viável, resistência a pragas e alto valor alimentício e nutritivo (Mota et al., 2000). Os frutos de quiabo podem ser classificados com relação a forma da secção transversal em angular ou circular (PEDROSA, 1983; MULLER, 1982; MOTA et al., 2000).

A aparência de frutos e hortaliças é caracterizada pelo tamanho, forma, cor, condições e ausência de desordens mecânicas, fisiológicas e patológicas (KAYS, 1999). A aparência externa é o primeiro critério utilizado pelo consumidor no julgamento da qualidade das hortaliças (KAYS, 1991; 1999). No entanto, outros atributos de qualidade além da aparência, como o sabor e aroma, textura, o valor nutritivo e de segurança alimentar, devem ser considerados na compra de um produto hortícola
(CHITARRA; CHITARRA, 1990; ABBOTT, 1999; AUERSWALD et al., 1999). O valor nutritivo é um atributo de qualidade muito importante, porém é o mais negligenciado na cadeia de comercialização de frutos, visto que não afeta a aparência (CHITARRA; CHITARRA, 1990). Entretanto, um amplo suprimento de alimentos balanceados nutricionalmente é de fundamental importância (SIDDHURAJU et al. 2002). Os componentes responsáveis pela qualidade nutricional dos produtos são vitaminas, minerais, açúcares solúveis, amido, fibras, hemiceluloses e lignina (KAYS, 1991). Adicionalmente, algumas substâncias químicas que condicionam valor nutritivo ao produto hortícola são também responsáveis pelo sabor, como é o caso dos sólidos solúveis, açúcares e ácidos orgânicos (AUERSWALD et al., 1999; MATTHEIS; FELLMAN, 1999).

As características da cultivar e a maturidade hortícola por ocasião da colheita são fatores críticos que influenciam nos atributos de qualidade dos produtos fres- cos. A maturidade hortícola é utilizada para definir o ponto ideal de colheita, ou seja, é o estádio do crescimento e desenvolvimento onde os frutos atingem o nível ideal de maturação, sendo tenros ou macio para o consumo "in natura" (SUOJALA, 2000). Esta maturidade hortícola, em quiabo, ocorre de 4 a 5 dias após a antese quando os frutos estão com aproximadamente $25 \%$ do seu tamanho máximo (MOTA et al., 2000), ou seja, com $2 \mathrm{~cm}$ de diâmetro, entre 5 a $7 \mathrm{~cm}$ de comprimento, dependendo da cultivar (DUZYAMAN, 1997), e quando o teor de fibra bruta for inferior a $6,5 \%$ (MULLER, 1982). Embora o quiabo não seja uma fonte rica de carboidratos, o fruto fresco oferece, à nutrição humana, fibra, proteína e vitamina $\mathrm{C}$, e as sementes que são fontes principalmente de proteínas e óleos (GOPALAKRISHNAN et al., 1982; MOTA et al., 2000).

O objetivo do presente trabalho foi realizar a caracterização físico-química e composição mineral dos frutos de quatro cultivares de quiabo colhidos no estádio de colheita comercial. 
Tabela 1. Valores médios de diâmetro, comprimento, peso da matéria fresca, teor relativo de água no pericarpo, porcentagem de matéria seca do fruto, porcentagem de umidade, clorofila total, clorofila a, clorofila b, vitamina C, amido, açúcar total, açúcar redutor, açúcar não redutor e fibra nas cultivares de quiabeiro Amarelinho, Red Velvet, Star of David e Mammoth Spinless. Viçosa, UFV, 2002.

\begin{tabular}{|c|c|c|c|c|c|}
\hline $\begin{array}{l}\text { Características } \\
\text { Físicas }\end{array}$ & Amarelinho & Red Velvet & $\begin{array}{l}\text { Star of } \\
\text { David }\end{array}$ & $\begin{array}{l}\text { Mammoth } \\
\text { Spinless }\end{array}$ & $\mathrm{CV}(\%)$ \\
\hline Diâmetro (mm) & $17,94 \mathrm{c}$ & $14,45 d$ & $33,16 a$ & $20,75 \mathrm{~b}$ & 5,59 \\
\hline Comprimento (mm) & $125,02 \mathrm{a}$ & $112,07 a b$ & $92,12 \mathrm{c}$ & $103,42 \mathrm{bc}$ & 6,97 \\
\hline Matéria fresca $(\mathrm{g})$ & $20,41 \mathrm{~b}$ & $9,42 \mathrm{c}$ & 37,47 a & $19,74 \mathrm{~b}$ & 12,63 \\
\hline Teor Relativo de Água (\%) & $91,65 \mathrm{a}$ & 89,77 a & 93,08 a & $87,67 \mathrm{a}$ & 4,05 \\
\hline Umidade (\%) & $91,01 \mathrm{ab}$ & 91,28 a & $89,77 \mathrm{c}$ & $89,97 \mathrm{bc}$ & 0,63 \\
\hline Matéria Seca (\%) & $8,98 \mathrm{bc}$ & $8,71 \mathrm{c}$ & $10,22 \mathrm{a}$ & $10,02 \mathrm{ab}$ & 6,09 \\
\hline \multicolumn{6}{|l|}{ Químicas } \\
\hline Clorofila Total $(\mu / g)$ & $30,54 \mathrm{c}$ & $32,24 \mathrm{bc}$ & $44,14 \mathrm{~b}$ & 65,74 a & 15,14 \\
\hline Clorofila a $(\mu / g)$ & $18,34 \mathrm{bc}$ & $17,96 \mathrm{c}$ & $26,22 \mathrm{~b}$ & 38,80 a & 16,97 \\
\hline Clorofila b $(\mu / g)$ & $12,20 \mathrm{c}$ & $14,28 \mathrm{bc}$ & $17,94 \mathrm{~b}$ & 26,94 a & 13,99 \\
\hline Vitamina C $(\mathrm{mg} / 100 \mathrm{~g})$ & $7,58 \mathrm{ab}$ & $8,91 \mathrm{a}$ & $6,03 \mathrm{~b}$ & $6,17 a b$ & 20,82 \\
\hline Amido (\%) & $1,23 \mathrm{a}$ & $0,98 \mathrm{a}$ & $1,21 \mathrm{a}$ & $1,16 \mathrm{a}$ & 26,39 \\
\hline Açúcar Total (\%) & $1,98 \mathrm{a}$ & $1,91 \mathrm{a}$ & $2,16 \mathrm{a}$ & $2,07 \mathrm{a}$ & 7,31 \\
\hline Açúcar Redutor (\%) & $1,86 \mathrm{a}$ & $1,37 \mathrm{~b}$ & $1,50 a b$ & $1,81 \mathrm{a}$ & 12,11 \\
\hline Açúcar não Redutor (\%) & $0,11 \mathrm{~b}$ & $0,53 \mathrm{ab}$ & $0,65 a$ & $0,25 \mathrm{ab}$ & 57,57 \\
\hline Fibra (\%) & $1,12 a$ & $0,87 a$ & $1,02 \mathrm{a}$ & $0,85 a$ & 15,96 \\
\hline
\end{tabular}

As médias seguidas de uma mesma letra, nas linhas, não diferem a 5\% pelo teste de Tukey $(\mathrm{P}>0,05)$.

\section{MATERIAL E MÉTODOS}

Os frutos de quiabo foram colhidos na Horta da Universidade Federal de Viçosa (MG), de janeiro a março de 2001, no estádio de colheita comercial quando estavam ainda tenros. Após a colheita, os frutos foram acondicionados em caixas plásticas, e transportados para o laboratório, onde foram selecionados.

As características físicas dos frutos avaliadas foram o diâmetro e comprimento, peso fresco e o teor relativo de água, conforme metodologia descrita por Catsky (1974). Foram avaliados ainda as porcentagens de matéria seca e de umidade, e os teores de clorofila a, b e total, pelo método descrito por Arnon (1949).

O teor de vitamina $\mathrm{C}$ dos frutos foi determinado segundo técnica recomendada pelo Instituto Adolfo Lutz (1985). Para determinação da porcentagem de açúcares solúveis totais, redutores e não redutores, utilizou-se método descrito por Somogy-Nelson e açúcares solúveis totais usando a reação de antrona (HODGE; HODFREITER, 1962). O apresentaram elevado a médio nível de angulosidade. A cultivar Amarelinho apresentou seção transversal circular, sendo esta a forma preferida pelo mercado brasileiro (MOTA et al., 2000). Esta preferência é justificada pelo conceito de que os frutos de formato angular seriam mais fibrosos; entretanto foi verificado, no presente trabalho, que não houve diferença significativa entre as cultivares angulares e circulares com relação ao teor de fibras na colheita comercial do fruto (Tabela 1). Segundo Rizzo et al. (2001), quando o quiabo dos dois formatos é cozido, os frutos angulosos são mais tenros que os cilíndricos.

Houve diferença significativa entre todas as cultivares, para todas as características físicas estudadas, exceto para o teor relativo de água no pericarpo (Tabela 1), com média geral de $90,5 \%$, demonstrando que todas as cultivares estudadas têm, aparentemente, o mesmo potencial para perder água e murchar após a colheita.

Os maiores comprimentos dos frutos foram verificados para as cultivares Amarelinho e Red Velvet com 125 e 112 $\mathrm{mm}$ (Tabela 1) respectivamente, enquanto os menores foram observados nos cultivares Star of David, com 92 mm, e Mammoth Spinless, com 103 $\mathrm{mm}$. As variações observadas nestas cultivares encontram-se na faixa de 100 a $140 \mathrm{~mm}$, sendo indicada por Duzyaman (1997) como ideal para colheita, com exceção da cultivar Star of David em que o comprimento ficou abaixo do valor mínimo desejado (Tabela 1).

O diâmetro e o peso fresco total dos frutos da cultivar Star of David foi superior aos das demais cultivares, enquanto que a Red Velvet teve os menores valores (Tabela 1). A faixa de variação do diâmetro foi de 14 a 33 mm para as cultivares testadas. A variação do diâmetro foi próxima àquela encontrada por Pedrosa et al. (1983), de 19 a 36 mm. Porém, estes autores avaliaram as medidas após o completo crescimento e desenvolvimento do fruto, mostrando que há reduzida ou nenhuma variação do diâmetro do ponto de colheita comercial até o completo desenvolvimento do fruto. A cultivar Star of David apresentou diâmetro de $33 \mathrm{~mm}$ no ponto de 
colheita comercial, enquanto que a cultivar Red Velvet teve 14 mm de diâmetro.

$\mathrm{O}$ peso da matéria fresca total dos frutos variou de 9,4 g a 37,5 g (Tabela 1). Estes pesos, no ponto de colheita comercial, são relativamente pequenos comparados ao máximo que pode atingir ao final do completo de desenvolvimento, com cerca de 50 g (KETSA; CHUTICHUDET, 1994).

A cultivar Star of David também teve maior teor de matéria seca e, consequentemente, o menor teor de umidade entre as cultivares, enquanto que a cultivar Red Velvet apresentou menor teor de matéria seca e maior teor de umidade. Os teores de matéria seca variaram de 8,7 a $10,2 \%$, e os de umidade de 89,8 a 91,3\%. Estes valores estão de acordo com a literatura, onde o teor médio encontrado foi de $10,4 \%$ para matéria seca e de $89,9 \%$ para o teor de umidade (MOTA et al., 2000).

As elevações do comprimento, diâmetro, matéria fresca e matéria seca são decorrentes dos mecanismos de crescimento e desenvolvimento, que ocorrem no fruto após a fecundação e continuam alterando-se entre ponto de colheita comercial até o completo desenvolvimento. Durante o desenvolvimento dos frutos, há aumento dos componentes de crescimento, como o número de células, volume celular e densidade celular que condicionam alterações nas matérias fresca e seca, paralelamente ao aumento do volume dos frutos (COOMBE, 1976).

Houve diferença significativa entre as cultivares para todas as características químicas avaliadas, exceto para açúcar total, amido e fibra (Tabela 1). A cor dos frutos é uma característica de grande importância comercial, principalmente ao considerar que o consumidor tem preferência por determinada cor externa do fruto, que varia do verde ao vermelho-púrpura (PEDROSA et al., 1983; MOTA et al., 2000). O teor de clorofila total da cultivar Amarelinho foi de 30,5 $\mu \mathrm{g} \mathrm{g}^{-1} \mathrm{MF}$ (matéria fresca), teor este menor que os 70,1 $\mu \mathrm{g} \cdot \mathrm{g}^{-1} \mathrm{MF}$, observados com esta cultivar por DellaJustina (1998). No campo de produção, normalmente ocorre variação da forma e cor dos frutos, e esta desuniformidade entre os frutos pode ter contribuído para a variação dos teores de clorofila observada por Carvalho (2002). A cultivar Mammoth Spinless apresentou os maiores teores de clorofilas a, b e total, enquanto os menores teores foram apresentados pelas cultivares Red Velvet e Amarelinho. As cultivares testadas neste experimento tiveram diferentes graus de cor verde, podendo atender as exigências dos vários mercados para consumo de frutos fresco.

A cultivar Red Velvet apresentou teor de vitamina $C$ de $8,9 \mathrm{mg} 100 \mathrm{~g}^{-1}$ $\mathrm{MF}$, sendo significativamente superior ao da cultivar Star of David, que apresentou teor de 6,0 8,9 mg $100 \mathrm{~g}^{-1} \mathrm{MF}$, enquanto as cultivares Amarelinho e Mammoth Spinless tiveram teores intermediários (Tabela 1). Estes teores estão próximos aos 5,5 8,9 mg $100 \mathrm{~g}^{-1}$ MF encontrados por Ketsa e Chutichudet (1994), trabalhando com a cultivar OK\#2, e inferiores aos 12,2 a $8,9 \mathrm{mg} 100 \mathrm{~g}^{-1} \mathrm{MF}$ encontrado por Della Justina (1998), trabalhando com a cultivar Amarelinho.

Não houve diferença entre as cultivares para os teores de amido e açucares totais dos frutos de quiabo (Tabela 1). Para todas as cultivares analisadas, o teor de amido foi de 0,98 a 1,23\% e o de açúcares totais de 1,91 a 2,16\% na matéria fresca. Os valores de amido foram superiores à média geral de $0,52 \%$ descritas na literatura (MOTA et al., 2000). Os teores de amido foram inferiores aos de açúcares totais, semelhante ao relatado por Thind et al. (1996), que avaliou a cultivar 'Pusa Sawani'. Estes autores verificaram, ainda, que os frutos em crescimento são drenos preferenciais para açúcares solúveis, pois a média geral de $2,03 \%$ é superior aos teores 1,13 e $0,67 \%$ encontrados em folhas e ramos, respectivamente.

Os teores de açúcares redutores e não redutores foram diferentes entre as cultivares (Tabela 1). Observou-se variação no sabor entre as cultivares, pois os açúcares, principalmente os redutores, como a frutose, são responsáveis pela sensação de "doçura" dos produtos hortícolas (CHITARRA; CHITARRA, 1990; AUERSWALD et al., 1999; MATTHEIS; FELLMAN, 1999). As cultivares Amarelinho e Mammoth Spinless apresentaram teores médios de açúcares redutores de 1,86 e 1,81\%, respectivamente, que são significativamente superiores ao teor de 1,37\% observado para a cultivar Red Velvet, enquanto a cultivar Star of David, com teor médio de $1,51 \%$, apresentou posição intermediária. Com relação aos teores médios de açúcares não redutores, observa-se que a cultivar Star of David apresentou teor significativamente superior à cultivar Amarelinho, com 0,65 e 0,11\% respectivamente. Já as cultivares Red Velvet e Mammoth Spinless ocuparam posição intermediária, tendo apresentado 0,53 e $0,25 \%$ de açúcares não redutores, respectivamente.

A maior parte dos compostos armazenados nos vacúolos do parênquima das células são açúcares solúveis redutores e não redutores (SUOJALA, 2000). Os açúcares redutores como a glicose, galactose e frutose são físiologicamente ativos, pelo poder de reduzir outras substâncias, enquanto os açúcares não redutores, como a sacarose, têm maior função de reserva e transporte, sendo que para serem metabolicamente ativos há necessidade de hidrólise em unidades simples de açúcares redutores (TAYS; ZEIGER, 1991). É possível que os frutos das cultivares Amarelinho e Mammoth Spinless, que apresentaram teores mais elevados de açúcares redutores, estejam em atividade metabólica mais intensa no ponto de colheita comercial, apresentando taxa respiratória e, conseqüentemente, maior síntese de material celular e crescimento. $\mathrm{O}$ inverso é observado para a cultivar Red Velvet, que apresentou maior teor de açúcares não redutores. No ponto de maturação da cenoura, a sacarose é o açúcar predominante (SUOJALA, 2000), entretanto, em frutos de quiabo no ponto de colheita comercial, houve, em todas as cultivares, maior teor de açúcares redutores em comparação aos não redutores.

O teor médio de fibra bruta não se alterou significativamente entre as cultivares, variando de 0,9 a $1,1 \%$ (Tabela 1), estando na faixa recomendada como ideal para colheita e consumo "in natura" de frutos de quiabo. Teores de fibra bruta superiores a 6,5\% tornam os frutos muito fibrosos e indesejáveis para o consumo (MULLER, 1982). 
Ketsa e Chutichudet (1994), trabalhando com a cultivar OK\#2, encontraram teor médio de fibras maior que os apresentados neste trabalho, com aproximadamente $2 \%$ no ponto de colheita comercial. Por outro lado, Suojala (2000) relata teor da ordem de $1,15 \%$ que está mais próximo dos teores encontrados neste trabalho.

Foi constatada considerável variabilidade para algumas características físicas, químicas e minerais entre as cultivares Amarelinho, Red Velvet, Star of David e Mammoth Spinless. Algumas características qualitativas importantes na conservação pós-colheita e no consumo in natura destacaram-se em algumas cultivares, como maior teor de vitamina C na cultivar Red Velvet; clorofila total, a e b, e açúcares redutores na cultivar Mammoth Spinless e o maior teor de açúcares redutores na cultivar Amarelinho.

\section{LITERATURA CITADA}

ABBOTT, J.A. Quality measurement of fruits and vegetables. Postharvest Biology and Technology, v.15, p.207-225, 1999.

ARNON, D.I. Copper enzyme in isolated chloroplasts polyphenoloxidase in Beta vulgaris. Plant Physiology, v.24, n.1, p.1-15, 1949. ASSOCIATION OF OFFICIAL ANALYTICAL CHEMISTS, AOAC. Official Methods of Analysis. 11 ed. Washington: 1992. 1115 p.

AUERSWALD, H.; SCHWARZ, D.; KORNELSON, C.; KRUMBEIN, A.; BRUECKNER, B. Sensory analysis, sugar and acid content of tomato at different EC values of the nutrient solution. Scientia Horticulturae, v.82, p.227-242, 1999.
BALBINO, J.M.S. Efeitos de hidrotermia, refrigeração e ethephon na qualidade pós-colheita do mamão (Carica papaya L.). Viçosa, MG: UFV, 1997. 104 f. (Tese de Doutorado) - Universidade Federal de Viçosa, Viçosa.

CARVALHO, M.J. Injúria por frio, respiração e produção de etileno pós-colheita em quiabo (Abelmoschus esculentus (L.) MOENCH.). 2002. (Tese de Mestrado) - Universidade Federal de Viçosa, Viçosa.

CATSKY, J. Water content. In: SLAVIK, B., ed Methods of studying plant water relations. Berlin: Springer-Verlag, 1974. p.121-31.

CHITARRA, M.I.F.; CHITARRA, A.B. Pós-colheita de frutos e hortaliças: fisiologia e manuseio. Lavras: ESAL/FAEPE, 1990. 320 p.

COOMBE, B.G. The development of fleshy fruits. Annual Review Plant Physiology, v.27, p.507-528, 1976.

DELLA-JUSTINA, M.E. Conservação pós-colheita do quiabo, influenciada por idade, dano mecânico, filme de PVC e temperatura. Viçosa, MG: UFV, 1998. 67 f. (Tese de Mestrado) - Universidade Federal de Viçosa, Viçosa.

DUZYAMAN, E. Okra: botany and horticulture. In: JANICK, J. Horticultural Reveiws, v.21, p.4172, 1997.

GOPALAKRISHNAN, N.; KAIMAL, T.N.B.; LAKSHMINARAYANA, G. Fatty acid changes in Hibiscus esculentus tissues during growth. Phytochemisrry, v.21, n.3, p.565-568, 1982. HODGE, J.E.; HODFREITER, B.R Determination of reducing sugars and carbohydrates. In: WILSTER, R.L., WOLFROM, M.L. (eds.). Methods in carbohydrate chemistry, New York, Academic Press, v.1, p.390-394, 1962 INSTITUTO ADOLFO LUTZ. Normas analíticas do Instituto Adolfo Lutz; métodos químicos e físicos para análises de alimentos. São Paulo: 1985. v.1, p.183.

KAYS, S.J. Postharvest physiology of perishable plant products. New York: Van Nostrand Reinhold, 1991. 453 p.

KAYS, S.J. Preharvest factors affecting appearance. Postharvest Biology and Technology, v.15, p.233-247, 1999.
KETSA, S.; CHUTICHUDET, B. Pod growth, development, biochemical changes and maturity indices of okra cv. OK\#2. Acta Horticulturae, v.369, p.368-377, 1994.

MATTHEIS, J.P.; FELLMAN, J.K. Preharvest factors influencing flavor of fresh fruit and vegetables. Postharvest Biology and Technology, v.15, p.227-232, 1999.

MOTA, W.F.; FINGER, F.L.; CASALI, V.W.D. Olericultura: Melhoramento Genético do Quiabeiro. Viçosa:UFV, Departamento de Fitotecnia, 2000. 144 p.

MULLER, J.J.V. Produção de sementes de quiabo (Abelmoschus esculentus (L) Moench). In: MULLER, J.J.V.; CASALI, V.W.D. “ed.” SEMINÁRIOS DE OLERICULTURA; 2a edição; Viçosa, MG, 1982. v.1, p.107-149.

PEDROSA, J.F.; MIZUBUTI, A.; CASALI, V.W.D.; CAMPOS, J.P. Caracterização morfológica de introduções de quiabeiro (Abelmoschus esculentus (L.) MOENCH.). Horticultura Brasileira, Brasília, v.1, n.1, p.1423, 1983.

RIZZO, A.A.N.; CHIKITANE, K.S.; BRAZ, L.T.; OLIVEIRA, A.P. Avaliação de cultivares de quiabeiro em condições de primavera em JaboticabalSP. Horticultura Brasileira, Brasília, v.19, n.2, suplemento CD-ROM, julho, 2001.

SIDDHURAJU, P.; MAKKAR, H.P.S.; BECKER,

$K$. The effect of ionising radiation on antinutritional factors and the nutritional value of plant materials with reference to human and animal food. Food Chemistry, 2002 (no prelo)

SUOJALA, T. Variation in sugar content and composition of carrot storage roots at harvest and during storage. Scientia Horticulturae, v.85, p.119, 2000.

TAIZ, L.; ZEIGER, E. Plant physiology. Redwood: Benjamin/Cummings, 1991. 565 p.

THIND, S.K.; MALIK, C.P.; MRIDULA Photosynthetic carbon fixation, translocation, yield and metabolite levels in okra (Abelmoschus esculentus L.) subjected to foliar application of aliphatic alcohols. Photosynthetica, v.33, n.2, p.255-261, 1996. 